Trinity University

Digital Commons @ Trinity

Psychology Faculty Research

Psychology Department

$12-2015$

\title{
Reducing Eating Disorder Risk Factors: A Pilot Effectiveness Trial of a Train-the-Trainer Approach to Dissemination and Implementation
}

\author{
Rebecca Greif \\ Carolyn Becker \\ Trinity University, cbecker@trinity.edu \\ Tom Hildebrandt
}

Follow this and additional works at: https://digitalcommons.trinity.edu/psych_faculty

Part of the Psychology Commons

Publication Details

International Journal of Eating Disorders

\section{Repository Citation}

Greif, R., Becker, C. B., \& Hildebrandt, T. (2015). Reducing eating disorder risk factors: A pilot effectiveness trial of a train-the-trainer approach to dissemination and implementation. International Journal of Eating Disorders, 48(8), 1122-1131. http://doi.org/10.1002/eat.22442

This Post-Print is brought to you for free and open access by the Psychology Department at Digital Commons @ Trinity. It has been accepted for inclusion in Psychology Faculty Research by an authorized administrator of Digital Commons@ Trinity. For more information, please contact jcostanz@trinity.edu. 
Running Head: REDUCING EATING DISORDER

\section{REDUCING EATING DISORDER RISK FACTORS IN MEMBERS OF A NATIONAL SORORITY: A TRAIN THE TRAINER APROACH TO DISSEMINATION AND IMPLEMENATION}

Rebecca Greif, PsyD ${ }^{\dagger 1}$, Thomas Hildebrandt, Psy.D. ${ }^{1}$, Carolyn Black Becker, Ph.D. ${ }^{2}$

${ }^{1}$ Eating and Weight Disorders Program, Department of Psychiatry, Mount Sinai School of Medicine, New York, NY USA.

${ }^{2}$ Department of Psychology, Trinity University, San Antonio, TX, USA

${ }^{\dagger}$ Corresponding author. Rebecca Greif, Eating and Weight Disorders Program, Mount Sinai

School of Medicine, One Gustave L. Levy Place, Box 1230. New York, NY 10029. Phone: 212659-8759. Fax: 212-849-2561 Email: rebecca.greif@mssm.edu. 


\begin{abstract}
Objective: Impediments limit dissemination and implementation of evidence-based interventions (EBIs), including lack of sufficient training. One strategy to increase implementation of EBIs is the train-the-trainer (TTT) model. The Body Project is a peer-led body image program that reduces eating disorder (ED) risk factors. This study examined the effectiveness of a TTT model at reducing risk factors in Body Project participants. Specifically, this study examined whether a master trainer could train a novice trainer to train undergraduate peer leaders to administer the Body Project such that individuals who received the Body Project (i.e., participants) would evidence comparable outcomes to previous trials. We hypothesized that participants would evidence reductions in ED risk factors, with effect sizes similar to previous trials. Method: Utilizing a TTT model, a master trainer trained a novice trainer to train undergraduate peer leaders to administer the Body Project to undergraduate women. Undergraduate women aged 18 years or older who received the Body Project intervention participated in the trial and completed measures at baseline, post-treatment, and five-month follow-up. Primary outcomes included body dissatisfaction, thin ideal internalization, negative affect, and ED pathology. Results: Participants demonstrated significant reductions in thin ideal internalization, ED pathology and body dissatisfaction at post-treatment and 5-month follow-up. At 5 months, using three different strategies for managing missing data, effect sizes were larger or comparable to earlier trials for 3 out of 4 variables. Discussion: Results support a TTT model for Body Project implementation and the importance of utilizing sensitivity analyses for longitudinal datasets with missing data.
\end{abstract}


Reducing Eating Disorder Risk Factors: A Pilot Effectiveness Trial of a Train-the Trainer Approach to Dissemination and Implementation

Research efforts have significantly increased the number of available evidence-based interventions (EBIs) for mental health conditions. Research, however, also indicates that EBIs are not commonly utilized in clinical settings ${ }^{1,2}$ due to a number of factors including lack of highly trained professionals and challenges in providing adequate clinical training to those with less background in a given intervention ${ }^{2,3}$. Currently, the standard model of post-graduate school clinical training involves attending a workshop led by an "expert" clinician coupled with reading a treatment manual. This model has several impediments: there are a limited numbers of "expert" clinicians who can train others in EBIs, expert clinicians are costly to employ ${ }^{4}$, and research indicates that this form of training increases therapist knowledge but does not improve therapist competency or clinical behavior ${ }^{5,6}$.

Due to limitations of current training models, researchers increasingly are investigating different methods aimed at effectively training clinicians in EBIs on a large scale. One method that has gained increasing attention, a train the trainer approach (TTT), involves an expert trainer who teaches identified non-expert individual(s) how to administer an intervention as well as how to train others to implement the intervention ${ }^{6}$. TTT is designed to address several of the limitations to traditional training models by teaching a larger pool of less expensive providers to train others in EBIs, which also increases the availability of local post-training supervision. Although there is a general dearth of research regarding $\mathrm{TTT}^{7}$, preliminary research suggests TTT is an effective training approach for a few different types of psychological interventions, including a guided self help version of cognitive behavioral therapy for binge eating behavior ${ }^{8}$ 
and motivational interviewing techniques ${ }^{9}$. Additional research regarding TTT, however, is critical to the advancement of mental health training procedures and improved dissemination of EBI's.

The Body Project, an empirically supported body image program conducted in a group format, has been shown to reduce both eating disorder (ED) risk factors and the risk of ED onset relative to assessment only control ${ }^{10}$. The Body Project is based on the dual pathway model of bulimia nervosa ${ }^{11}$ which posits that sociocultural pressures to be thin and investment in the thinideal (i.e., thin-ideal internalization) lead to body dissatisfaction. Body dissatisfaction then theoretically contributes to increases in dieting and negative affect which in turn can lead to onset of ED behaviors in vulnerable individuals ${ }^{11}$. Consistent with the theory of cognitive dissonance $^{12}$, the Body Project centers on encouraging participants to engage in behaviors that actively challenge the thin-ideal which should, in turn, lead to a decline in thin-ideal internalization and a subsequent reduction in the other ED risk factors.

The Body Project is supported by a significant efficacy and effectiveness evidence base ${ }^{13-17,18,19 \text {, }}$ 20, 21,22, 23-25, 26,27, 28 . Though other ED prevention programs, such as the Health Weight Intervention ${ }^{10}$ and Student Bodies ${ }^{29}$ are also empirically supported, The Body Project is the program with the largest research base, including independent replication ${ }^{30}$. More specifically, repeated trials indicate that the Body Project reduces body dissatisfaction, thin-ideal internalization, dietary restraint, bulimic pathology, and negative affect with many changes largely maintained through 12-36 month follow-up ${ }^{10,17,28,31,32}$. As noted above, research also indicates that the Body Project reduces the risk of ED onset relative to assessment only control ${ }^{10}$. It is important to highlight, however, that this finding is not unique to the Body Project. More 
specifically, both the Body Project and the Healthy Weight program have yielded comparable reductions in eating disorder onset relative to assessment only control ${ }^{10}$. The Healthy Weight program has also produced comparable reductions in risk factors in both efficacy and effectiveness trials ${ }^{10,17}$.

As The Body Project has evolved, dissemination of the program has relied on a number of strategies described in the literature to improve scalability of psychological interventions (i.e., the degree to which implementation of an intervention can be "scaled up" "33,34). For instance, in its original form, the program was administered to groups of participants by a doctoral level psychologist; however it was subsequently task-shifted ${ }^{33,34}$ from very or moderately expensive group leaders (i.e., doctoral or masters level providers) to less expensive group leaders (e.g., undergraduate peers). A number of studies support the viability of this scaling strategy with the Body Project ${ }^{14,15,17,28}$. As part of this task-shifting approach, training procedures were developed in which a doctoral level psychologist directly trained undergraduate peer leaders to administer the program. During these standardized intensive training workshops, peer leaders conducted role-plays of simulated sessions and received feedback from the doctoral level trainer to ensure they reached an adequate level of competency.

This task-shifting dissemination strategy was used to implement the program at several universities across the country; however, it soon became clear that there were limitations to this approach. More specifically, a dearth of competent trainers, the inability of these few trainers to travel to universities around the country secondary to demands from their main source of employment, and the significant expense of hiring doctoral level trainers were impediments to broader dissemination of the program. It was determined that a TTT model, in which a highly 
experienced doctoral level psychologist (i.e., master trainer) would train non-expert providers (i.e., novice trainers) to subsequently train undergraduate peer leaders, might alleviate these impediments and therefore be advantageous. This approach was subsequently implemented in two manners.

The first attempt at implementing a TTT model for The Body Project involved a pilot study in which consultants from Tri Delta (a national sorority) ${ }^{1}$ were trained to implement the program by a master trainer and then were deployed to train undergraduate peer leaders at an individual sorority chapter ${ }^{31}$. Results from this pilot study indicated that ED risk factors were reduced; however, effect sizes and number of participants who completed the program were lower than in previous trials.

The second attempt at implementing a TTT approach was conducted at a centralized training program created for The Body Project, known as the Body Image Academy (BIA). BIA involved an intensive 2-day training experience in which undergraduates from institutions across the country were trained to be peer leaders (referred to as "Track 1"; see Kilpela et al" for a detailed description of Track 1). BIA also involved a "Track 2" which targeted university professionals (e.g., faculty, dieticians, staff from counseling centers, and others). During BIA, university professionals simultaneously were trained-to-train the undergraduate students in BIA Track 1 with the expectation that they then would be competent to train undergraduate peer leaders back at their home institutions. The TTT model used in Track 2 at BIA was based on significant clinical experience with training but had not been studied. Thus, we lacked clear data

\footnotetext{
${ }^{1}$ A National Sorority is a national society or club for undergraduate women. A Sorority Chapter is a campus-based organization of a National Sorority.
} 
that demonstrated whether or not the Body Project retained its effectiveness at a participant level when peer leaders were trained by trainers who had participated in a 2-day TTT training.

The primary aim of the present pilot study was to investigate the degree to which a specific 2-day TTT model would produce participant outcomes (i.e., effectiveness) comparable to previous controlled trials of the Body Project. Proctor et al. ${ }^{36}$ note that there are multiple levels of outcomes that can be explored in dissemination/implementation research, and offer a taxonomy that includes: implementation outcomes (e.g., adoption, fidelity), service outcomes (e.g., efficiency, effectiveness), and client outcomes (e.g., satisfaction, function). In this trial, we sought to investigate the primary service outcome that university professionals reported to us was the most important to them, namely effectiveness. Effectiveness refers to the degree to which the program produces desired outcomes with participants. Thus, in this trial we examined whether a novice trainer who was trained by a master trainer over a 2-day period could train undergraduate peer leaders to administer the Body Project and yield comparable effectiveness outcomes to previous trials of The Body Project ${ }^{15,17,31}$ using a benchmarking approach $^{37,38}$. We operationalized effectiveness as reductions in participant-level ED risk factors assessed in previous controlled research. We hypothesized that participants would evidence significant reductions in ED risk factors, and that effect sizes would be similar to previous trials of The Body Project.

\section{Methods}

\section{Participants}

The Body Project was implemented with members of a national sorority (i.e., a women's social organization at an undergraduate institution) in a large university in the Northeastern 
portion of the United States who were 18 years or older. Sorority members could volunteer to be trained as peer leaders or participate in the 2-session group program.

Because the sorority chapter chose to strongly encourage participation in the Body Project (either as a peer leader or a participant) the program and study were separated from one another. More specifically, sorority members could complete The Body Project groups and elect not to be participants in this study. The study consisted of completion of the assessments, and only was conducted on individuals who received the Body Project as participants (i.e., peer leaders were not included in this study). Of the 124 sorority members who were eligible to receive the Body Project (i.e., all members of the sorority except those who volunteered to be peer leaders), 72 members participated in the Body Project between Spring 2009 and Spring 2010 and all members who participated in the program also consented to the research study and completed the baseline assessment (T1). Women who met criteria for an ED ( $n=8)$ were removed from analyses, resulting in a total sample of 64 participants. Of the 64 participants, 46 (71.9\%) completed the second session of The Body Project and all members who completed the second session also completed the post-treatment assessment (T2). Twenty-eight (43.8\%) participants completed 5-month follow-up assessments (T3). See Figure 1.

\section{Procedures}

In September 2008, prior to the commencement of The Body Project, members of the sorority attended a sorority chapter meeting where the content and history of the Body Project was discussed. The peer-led nature of the program was also explained. Sorority members then had the opportunity to volunteer to be trained as a peer leader or to be a participant in the Body Project. All members of the sorority were encouraged to volunteer either as a peer leader or participant; however, this was not mandatory. As noted above, the research study and The Body 
Project were maintained separately. At this meeting, the voluntary research study, which was for participants only (i.e., not peer leaders) also was explained. Sorority members were informed that they could receive The Body Project without taking part in the study.

This study commenced in March 2009 and data were collected through Spring 2010. The study and The Body Project program were approved by the sorority president, the University Greek Council (a governing body that oversees sorority activities on campus), and the University Institutional Review Board. A member of the sorority, referred to as the Body Image Coordinator, was appointed to serve as a liaison between the research team and the sorority. Sorority members who agreed to participate in the study in Spring $2009(n=49)$ completed the consent form and baseline questionnaires (see "Measures" section, below) directly prior to the first Body Project session. Members generated their own ID numbers so that data would be anonymous. Participants completed post-treatment questionnaires directly after completion of the second Body Project session; they also completed five-month follow-up questionnaires at a sorority meeting. We audio taped Body Project sessions to assess peer leader adherence to the treatment protocol.

After the sorority's initial implementation of The Body Project in Spring 2009 sorority officers decided to implement the program each semester with new sorority members. We trained new peer leaders using the same TTT training protocol to replace peer leaders who had graduated. Data were collected on Body Project participants who joined the sorority in Fall 2009 $(n=11)$ and Spring $2010(n=12)$. This resulted in three cohorts of participants.

Training Procedures. Multiple peer leader trainings occurred in the context of this trial. The first 2- day training workshop (i.e., Trainer Training) occurred in Fall 2008 in which the a master trainer simultaneously trained several graduate students, including the first author, as 
Body Project trainers and trained undergraduate peer leaders. This training was similar to the trainings that occurred at BIA with the graduate students serving in the role previously occupied by university professionals. The next training workshop (i.e., Peer Leader Training) occurred in Winter 2009 in which the first author, who was now a trainer, trained additional undergraduate peer leaders (i.e., "Peer Leader Training"). Both types of trainings are detailed, below.

\section{Trainer Training.}

In October 2008, a master trainer traveled to the research site and conducted a two-day training that mirrored the procedure used in Body Image Academy. This training consisted of two full days. Twelve undergraduate students served as peer leaders in training and the first author and several other graduate students served as trainers in training. The 12 peer leaders were divided into 4 teams of three students and proceeded to take turns leading an abbreviated version session 1 on day 1 and session 2 on day 2, using the highly scripted Body Project manual. After the first team completed their trial of session 1, the master trainer modeled how to give supervision and highlighted common training issues. Supervision involved providing feedback with regard to both content (e.g., forgetting to administer an intervention in the manual) and process (e.g., reflective listening, facilitating conversation among group participants). Subsequently, the graduate students (trainers in training) provided feedback after each team completed the abbreviated version of session 1 and received behavioral supervision on their supervision from the master trainer. On day 2 , the same process was repeated. Thus, graduate students were able to practice giving supervision 3 times on each day and received a total of 6 rounds of supervision from the master trainer. Throughout the training, the master trainer also provided clarification and suggestions for handling challenging sections/participants. 
Peer leader training. Five additional sorority members who volunteered to be peer leaders after the aforementioned training attended a separate peer leader training session in February 2009. The full-day training was led by the first author. During training, each peer leader team implemented abbreviated program sessions (i.e., 40 minutes instead of 2 hours) using a Body Project manual, while the other teams acted as participants. Peer leaders received supervision from the first author regarding their simulated session. Similar to the other training, supervision involved providing feedback with regard to both content (e.g., forgetting to administer an intervention in the manual) and process (e.g., reflective listening, facilitating conversation among group participants). New peer leaders were trained as needed using this same procedure for the following year.

Body Project. After training was completed, the undergraduate peer leaders administered the Body Project to groups of sorority women (i.e., participants). The Body Project consisted of two, 2-hour group sessions administered by two to four peer leaders to groups consisting of five to nine participants. During the first session, participants identified the thin ideal, discussed the origin of the thin ideal and how it is perpetuated in our society, discussed the costs of pursuing the thin ideal, and delineated past situations when they felt pressure to pursue the thin ideal and how they would currently respond to that pressure. Between the first and second session participants were asked to stand in front of a mirror and list their positive physical and emotional qualities. The second session consisted of role-plays in which peer leaders acted as a "thin idealist" and small groups of participants attempted to challenge their pursuit of the thin ideal. Participants also discussed ways to challenge common "fat talk statements," discussed ways that sorority members can resist the thin ideal both on an individual level and 
collectively (i.e., body activism), discussed possible barriers to body activism and how to overcome these barriers, and committed to a self-affirmation homework exercise.

\section{Measures}

The primary dependent variables were thin ideal internalization, negative affect, body dissatisfaction, and bulimic pathology.

Thin ideal internalization. Thin ideal internalization was assessed using an 8-item modified version of the Ideal-Body Stereotype Scale-Revised (IBSS-R) ${ }^{39}$. Participants responded to statements such as "Thin women are more attractive" using a 5-point Likert scale ranging from 1 (strongly disagree) to 5 (strongly agree). Items are summed and then averaged. The IBSS-R has good internal consistency (alpha $=.83$ to .91$)$, test-retest reliability $(\mathrm{r}=.67$ to .80 ) and convergent and predictive validity ${ }^{39,40}$. The internal consistency of the IBSS-R in the present study was 0.77 at baseline, 0.86 at post-treatment, and 0.76 at 5-month follow-up.

Negative affect. Negative affect was assessed using the Positive and Negative Affective Schedule (PANAS). Participants reported whether they had experienced 20 negative emotions during the past week using a 5-point Likert scale ranging from 1 (not at all) to 5 (extremely). PANAS has demonstrated good internal consistency $(\alpha=.95)$, reliability and validity ${ }^{41}$. The internal consistency of the PANAS in the present study was 0.91 at baseline, 0.94 at posttreatment, and 0.97 at 5-month follow-up.

Body dissatisfaction. Body dissatisfaction was assessed using the Satisfaction and Dissatisfaction with Body Parts Scale (SD-BPS) ${ }^{42}$. Participants rated their dissatisfaction with nine body parts (e.g. stomach, thighs, hips) using a Likert scale ranging from 1 (extremely satisfied) to 5 (extremely dissatisfied). This scale has good internal consistency $(\alpha=.94)$, 3- 
week test-retest reliability $(r=.90)$ and predictive validity for bulimic symptom onset ${ }^{23}$. The internal consistency of the Satisfaction and Dissatisfaction with Body Parts Scale in the current study was 0.95 at baseline, 0.92 at post-treatment, and 0.94 at 5-month follow-up.

Bulimic pathology. Bulimic pathology was assessed using the bulimic composite score of the Eating Disorder Examination-Questionnaire (EDE-Q) ${ }^{43}$ which assesses eating behaviors and attitudes over the past 28 days (e.g., "Over the past 28 days how many times have you made yourself sick (vomit) as a means of controlling your shape or weight?"). The EDE-Q is a selfreport version of the Eating Disorder Examination $(E D E)^{44}$, a semi-structured interview used to assess EDs. The EDE-Q has good test-retest reliability ( $r=0.81$ to 0.94$)$ and internal consistency $(\alpha=.78 \text { to } 0.93)^{45,46}$. The bulimic pathology subscale was derived by summing the diagnostic items of the EDE-Q and then computing an average score. The internal consistency of this subscale was 0.80 at baseline, 0.78 at post-treatment, and 0.72 at 5 -month follow-up.

\section{Statistical Analyses}

Given the relatively high rate of participant dropout, we utilized three different statistical models for analyzing missing data in the context of this longitudinal study. There is currently no empirical basis for choosing one statistical model versus another and therefore researchers have suggested the use of sensitivity analyses, such as the one used in this study, which fit multiple statistical models to the same data ${ }^{47}$. MAR models are based on the assumption that the likelihood of missing data on variable Y (e.g., thin ideal internalization, TIIS) is not related to the unobserved values of Y (e.g., missing values for TIIS), though they may be related to other variables in the analysis $^{48,49}$. In contrast, MNAR models posit that there is a relationship between the outcome variable and the likelihood of missing data. The Diggle Kenward model consists of a growth curve model plus a regression equation that predicts the probability of 
missing data at a specific timepoint based on the repeated measures variable (Y). This model also assumes a normal distribution for $\mathrm{Y}$, which seems reasonable based on the dependent variables in this study, yet is impossible to test. The Pattern Mixture Model stratifies a study sample into subgroups that have similar missing data patterns and subsequently estimates separate growth models for each pattern. This model assumes homogeneity of growth within each group.

Analysis of intervention effects was conducted using latent growth curve modeling ${ }^{50}$. All analyses were conducted using Mplus 6.12 $2^{51}$. Linear and non-linear models were compared to establish the best fit for the data utilizing a missing at random (MAR) model for missing data. The best fitting model was determined using comparative fit index (CFI) and root mean square of approximation (RMSEA). CFI values $>0.95$ and RMSEA values $<0.06$ were considered evidence for a good model fit to the data ${ }^{52}$. Separate latent growth curve models for each of the four dependent variables at three time points (i.e., baseline, post-treatment, and 5-month followup) were constructed using a non-linear spline to estimate deceleration of change over follow-up. Analyses also were conducted using two missing not at random models (MNAR): the DiggleKenward $^{53}$ which is one type of Selection Model and the Pattern Mixture Model ${ }^{54}$. The purpose of this sensitivity analysis was to compare effect sizes and changes in treatment based on different models for missing data.

All Body Project sessions were audio-recorded and fifty percent of tapes were coded by the first author for adherence to the intervention manual. An adherence measure was used which lists specific tasks that peer facilitators were intended to implement (e.g., discussed origins of the thin ideal and elicited sources such as media, fashion industry, weight loss industry). Each task 
was rated on a 4-point Likert scale which ranged from 0 (did not complete) to 3 (fully

completed). All coded tapes exhibited strong adherence to the treatment protocol.

\section{Comparison Studies.}

As this was a benchmarking study, results from this trial were compared to the results from three previous trials of The Body Project (Becker et al., 2008, Perez et al., 2010, Becker et al 2010). Each of these studies is described, in turn. In Becker et al. (2008), 188 sorority members were randomized to receive The Body Project or an intervention referred to as Media Advocacy, which was identical to The Body Project except it excluded the dissonance-inducing activities. All peer leaders were undergraduate sorority members trained by the master trainer who developed the peer lead version of this program. Initial participation rates were strong $(92 \%)$ as well as retention rates at post-intervention (90.5\%), seven week follow-up (87.3\%) and eight month follow up (74.5\%). In a second study, Perez and colleagues (2010) examined whether The Body Project could be implemented on a semi-mandatory basis at a large state university with TriDelta members using the aforementioned TTT model in which consultants from Tri Delta (a national sorority) were trained to implement the program by a master trainer and then were deployed to train undergraduate peer leaders at an individual sorority chapter. One hundred and eighty four members of Tri Delta participated in this program and evidenced reduced rates of participation at post-treatment $(79.1 \%)$ and one year follow up $(62.6 \%)$ compared to previous trials. Finally, Becker and colleagues (2010) compared The Body Project to a modified version of the Health Weight Prevention program (MHW), which is another empirically supported ED prevention program. Peer leaders were undergraduates trained by same master trainer as in the previous studies. One hundred and six sorority members were randomized to The Body Project or MHW and initial participation rates (97\%) and retention 
rates were strong at post-treatment $(98.1 \%)$, eight week follow up (81\%(, eight month follow-up (81\%) and 14-month follow up (74\%).

\section{Results}

\section{Sample Characteristics}

Of the 72 women who participated in the study, eight participants were excluded because they met criteria for a current ED. This resulted in a final sample of 64 participants with a mean age of $19.86(\mathrm{SD}=1.32)$. Participants' mean body mass index $(\mathrm{BMI})$, based on self-reported height and weight, was $25.38(\mathrm{SD}=4.85)$ with a range from 17.33 to 36.90 . Note that one participant with a BMI of 17.33 did not endorse any shape or weight concerns and was therefore not excluded from the study despite being underweight. The majority of participants identified their ethnicity as Caucasian $(78.1 \%)$. The remainder of participants identified themselves as Hispanic (12.5\%), Asian (4.7\%), Black (1.6\%) and "Other" (3.1\%). The grade level of participants was as follows: $34.4 \%$ were in their sophomore year of college, $25 \%$ were juniors, $18.8 \%$ were seniors, and $17.2 \%$ were freshman.

T-test analyses did not reveal statistically significant differences on participants' baseline scores on thin ideal internalization, negative affect, body dissatisfaction, bulimic pathology, and BMI between cohort 1 (i.e., Spring 2009) cohort 2 (i.e., Fall 2009), or cohort 3 (i.e., Spring 2010). Analyses were also conducted to determine if there were predictors for dropout at T2 or T3. Logistic regression analyses did not identify any predictors of dropout at end of treatment (See Table 1) or 5-month follow-up (See Table 2).

\section{Primary Outcomes}


Table 3 consists of the estimated model means, standard deviations, intercept and slope for the four dependent variables (thin ideal internalization, negative affect, body dissatisfaction, and bulimic pathology) at all three time points (baseline, post-treatment, and 5- month followup) for all three analytic models (Missing at Random, MAR; Diggle-Kenward, DK; Pattern Mixture Model, PMM). The slope for all three models indicate that there was significant reduction in participants' level of thin ideal internalization (IBSS-R), body dissatisfaction (SDBPS) and Bulimic Pathology (EDEQ-BN) from baseline to 5-month followup. The slope for all three models of PANAS indicates that there was not a significant change in the level of participants' negative affect from baseline to 5-month follow-up.

The effect sizes of this study and the effect sizes found in Becker et al. (2008), Becker et al. (2010), and Perez et al. (2010) are listed in Table 4. Reduction in thin ideal internalization at 5-month follow-up in this study was larger than in previous trials and the effect size for reduction in bulimic pathology and body dissatisfaction were comparable to previous trials. Reductions in negative affect were not significant.

\section{Sensitivity Analyses}

The three analyses resulted in significant differences with regard to effect sizes (see Table 4). With the exception of body dissatisfaction, PMM analyses resulted in lower estimates of effect sizes relative to the other two models. In general, the three analyses did not yield significant differences with regard to model slope. One exception is that the estimated slope for EDEQ-BN was comparatively higher using DK analyses $\left[\mu_{\text {slope }}=-0.427(S E=0.106)\right]$ and PMM analyses $\left[\mu_{\text {slope }}=-0.431(S E=0.106)\right]$ as compared to MAR analyses $\left[\mu_{\text {slope }}=-0.228(S E=0.060]\right.$.

\section{Discussion}


The primary aim of this dissemination study was to investigate whether or not the Body Project retained effectiveness when a 2-day TTT approach was used to train novice trainers of peer leaders. More specifically, this study examined whether individuals who participated in the Body Project Program, led by peer leaders who were trained by the novice trainers, would evidence significantly reduced key ED risk factors and yield effect sizes comparable to previous controlled trials of the Body Project using a benchmarking approach. Benchmarking involves comparing effect sizes across trials so that less controlled trials (e.g., when research moves from efficacy through effectiveness to dissemination) can be compared to more controlled trials ${ }^{37}$ Consistent with the study's hypotheses, participants demonstrated significant reductions in thin ideal internalization, bulimic pathology and body dissatisfaction at post-treatment and 5-month follow-up, though there was a trend toward increased scores from post-intervention to follow up. We should note that given the reduced rates of participation and study retention, it is difficult to make strong conclusions based on the results of this study. Nonetheless, at 5 months, using three different strategies for managing missing data, effect sizes were either larger or comparable to earlier trials for 3 out of 4 variables (thin-ideal internalization, body dissatisfaction, and ED pathology). Importantly, these are the three most salient variables and are most directly targeted by the Body Project. Moreover, recordings of Body Project sessions support that peer leaders, trained using this TTT approach, exhibited strong adherence to the intervention protocol. Although this was not a primary outcome of this study, it provides some additional support for the TTT approach.

Although one must be cautious in drawing conclusions from this pilot study given the relatively low retention rates, relatively high rates of participant dropout, and absence of a control condition, taken as a whole, results appear to provide preliminary support for the 
effectiveness of a 2-day TTT model for the Body Project. This is important both for the TTT model generally and for dissemination of the Body Project specifically. Considering the TTT strategy, this study provides further support for this model of increasing scalability of EBIs by training lower cost providers to train other providers. In turn, this increases the number of individuals who can be properly trained in these interventions, which increases the number of individuals reached as program participants.

In terms of the Body Project specifically, these results provide preliminary empirical support for one of the training methods that has been used in the Body Project dissemination efforts. Further, although the BIA is no longer in existence we have continued to use the twoday TTT approach to facilitate ongoing dissemination of the Body Project. As in the present study, this usually involves sending a master trainer to a university to train both trainers and peer leaders. These dissemination efforts have resulted in significant positive qualitative feedback as well as reports from universities that their own internal assessment (using benchmarking) supported the approach. However, this is the first study that directly tested this specific Body Project TTT dissemination model.

This study highlights the importance of how one handles missing data in the context of a longitudinal prevention program, particularly given that predictors of dropout were difficult to identify. The three different types of analyses conducted in this trial yielded different results and PMM analyses yielded outcomes most consistent with previous trials of The Body Project. Sensitivity analyses, such as the ones conducted in this study, are therefore particularly valuable because they provide the ability to better understand variable outcomes. For instance, in this study, a more conservative effect was found when missingness was considered a pattern within a 
subgroup. In larger trials with more observation timepoints, PMM analysis may enhance our nuanced understanding of how symptom change over time is related to dropout.

\section{Limitations}

There are several limitations to this study. The reduced rate of program participation coupled with the relatively high rate of participant dropout in this study (i.e., twenty nine out of the seventy two participants in the study completed follow up assessments) makes it difficult to draw strong conclusions about the effectiveness of the TTT model because it is unknown how members who did not participate in, or dropped out early from, the study would have responded to The Body Project. The sample size is also small which reduces statistical power. The followup period of 5 months is also relatively short for a prevention program. Moreover, the mean BMI was 25, which is the high end of a healthy BMI range; this may reflect a biased sample. In addition, there was no control group and therefore it is possible that the results are due to factors that are not associated with The Body Project. For example, it is possible that demand effects impacted participant ratings on outcome measures. However, previous studies of cognitive dissonance interventions used waitlist conditions ${ }^{23}$ and comparison of the results obtained in this study with previous waitlist conditions support the effectiveness of The Body Project. For instance, 5 month effect sizes in the present study (e.g., bulimic pathology $d=.45-.62$ ) largely benchmarked against the 6-month Body Project results from Stice et al.'s ${ }^{23}$ highly controlled efficacy trial (bulimic pathology $d=.56$ ), in which the Body Project yielded superior results to both an assessment only control and expressive writing control condition at 6 months.

\section{Conclusion}

In summary, this study suggests that a train-the-trainer model is largely effective for dissemination of the Body Project program. Three different types of data analysis were utilized 
in this study and confirm these findings. However, these results should be interpreted with caution given the low rates of program participation and retention and absence of a control condition. Future research should further examine how a train-the-trainer model can be used to further disseminate the Body Project as well as other psychological interventions. Moreover, sensitivity analyses should be utilized more frequently with longitudinal datasets involving missing data. 


\section{References}

1. Shafran R, Clark DM, Fairburn CG, et al. Mind the gap: Improving the dissemination of CBT. Behav Res Ther. Nov 2009;47(11):902-909.

2. Kazdin AE, \& Blase, S.L. . Rebooting psychotherapy research and practice to reduce the burden of mental illness. Perspectives on Psychological Science. 2011;6(1):21-37.

3. Weissman MM, Verdeli H, Gameroff MJ, et al. National survey of psychotherapy training in psychiatry, psychology, and social work. Arch Gen Psychiatry. Aug 2006;63(8):925-934.

4. Olmstead T, Carroll KM, Canning-Ball M, Martino S. Cost and cost-effectiveness of three strategies for training clinicians in motivational interviewing. Drug and alcohol dependence. Jul 1 2011;116(1-3):195-202.

5. Beidas RS, Kendall PC. Training Therapists in Evidence-Based Practice: A Critical Review of Studies From a Systems-Contextual Perspective. Clinical psychology : $a$ publication of the Division of Clinical Psychology of the American Psychological Association. Mar 2010;17(1):1-30.

6. Herschell AD, Kolko DJ, Baumann BL, Davis AC. The role of therapist training in the implementation of psychosocial treatments: a review and critique with recommendations. Clinical psychology review. Jun 2010;30(4):448-466.

7. Ray ML, Wilson MM, Wandersman A, Meyers DC, Katz J. Using a training-of-trainers approach and proactive technical assistance to bring evidence based programs to scale: an operationalization of the interactive systems framework's support system. American journal of community psychology. Dec 2012;50(3-4):415-427. 
8. Zandberg LJ, Wilson GT. Train-the-trainer: implementation of cognitive behavioural guided self-help for recurrent binge eating in a naturalistic setting. European eating disorders review : the journal of the Eating Disorders Association. May 2013;21(3):230237.

9. Martino S, Ball SA, Nich C, Canning-Ball M, Rounsaville BJ, Carroll KM. Teaching community program clinicians motivational interviewing using expert and train-thetrainer strategies. Addiction. Feb 2011;106(2):428-441.

10. Stice E, Marti CN, Spoor S, Presnell K, Shaw H. Dissonance and healthy weight eating disorder prevention programs: Long-term effects from a randomized efficacy trial. Journal of Consulting and Clinical Psychology. Apr 2008;76(2):329-340.

11. Stice E. A prospective test of the dual-pathway model of bulimic pathology: mediating effects of dieting and negative affect. J Abnorm Psychol. Feb 2001;110(1):124-135.

12. Festinger L. A theory of cognitive dissonance. Oxford, England: Row; 1957.

13. Becker CB, Smith, L.M., \& Ciao, A.C. . Reducing eating disorder risk factors in sorority members: A randomized trial. Behavior Therapy 2005;36:245-253.

14. Becker CB, Smith, L.M., \& Ciao, A.C. . Peer facilitated eating disorder prevention: A randomized effectiveness trial of cognitive dissonance and media advocacy. Journal of Counseling Psychology. 2006;53:530-555.

15. Becker CB, Bull S, Schaumberg K, Cauble A, Franco A. Effectiveness of peer-led eating disorders prevention: a replication trial. J Consult Clin Psychol. Apr 2008;76(2):347-354.

16. Becker CB, Bull, S., Smith, L.M., Ciao, A.C. Effects of being a peer leader in an eating disorder prevention program: Can we further reduce eating disorder risk factors? Eating disorders. 2008(b);16(5):444-459. 
17. Becker CB, Wilson C, Williams A, Kelly M, McDaniel L, Elmquist J. Peer-facilitated cognitive dissonance versus healthy weight eating disorders prevention: A randomized comparison. Body image. Sep 2010;7(4):280-288.

18. Matusek JA, Wendt SJ, Wiseman CV. Dissonance thin-ideal and didactic healthy behavior eating disorder prevention programs: results from a controlled trial. The International journal of eating disorders. Dec 2004;36(4):376-388.

19. Roehrig M, Thompson JK, Brannick M, van den Berg P. Dissonance-based eating disorder prevention program: a preliminary dismantling investigation. The International journal of eating disorders. Jan 2006;39(1):1-10.

20. Stice E, Mazotti L, Weibel D, Agras WS. Dissonance prevention program decreases thinideal internalization, body dissatisfaction, dieting, negative affect, and bulimic symptoms: A preliminary experiment. The International journal of eating disorders. Mar 2000;27(2):206-217.

21. Stice E, Chase A, Stormer S, Appel A. A randomized trial of a dissonance-based eating disorder prevention program. The International journal of eating disorders. Apr 2001;29(3):247-262.

22. Stice E, Trost A, Chase A. Healthy weight control and dissonance-based eating disorder prevention programs: results from a controlled trial. Int. J. Eating Disord. Jan 2003;33(1):10-21.

23. Stice E, Shaw H, Burton E, Wade E. Dissonance and healthy weight eating disorder prevention programs: A randomized efficacy trial. Journal of Consulting and Clinical Psychology. Apr 2006;74(2):263-275. 
24. Stice E, \& Presnell, K. . The body project: Promoting body acceptance and preventing eating disorders, facilitator guide. New York: Oxford University Press; 2007.

25. Stice E, Marti CN, Spoor S, Presnell K, Shaw H. Dissonance and healthy weight eating disorder prevention programs: long-term effects from a randomized efficacy trial. $J$ Consult Clin Psychol. Apr 2008;76(2):329-340.

26. Stice E, Rohde P, Gau J, Shaw H. An effectiveness trial of a dissonance-based eating disorder prevention program for high-risk adolescent girls. J Consult Clin Psychol. Oct $2009 ; 77(5): 825-834$.

27. Stice E, Rohde P, Shaw H, Gau J. An effectiveness trial of a selected dissonance-based eating disorder prevention program for female high school students: Long-term effects. $J$ Consult Clin Psychol. Aug 2011;79(4):500-508.

28. Stice E, Rohde P, Durant S, Shaw H, Wade E. Effectiveness of peer-led dissonance-based eating disorder prevention groups: results from two randomized pilot trials. Behav Res Ther. May 2013;51(4-5):197-206.

29. Winzelberg AJ, Eppstein D, Eldredge KL, et al. Effectiveness of an Internet-based program for reducing risk factors for eating disorders. J Consult Clin Psychol. Apr 2000;68(2):346-350.

30. Becker CB, Mackenzie, K, Stewart, T. . Cognitive and behavioral approaches to the prevention of eating disorders. Hoboken: John Wiley \& Sons, Ltd.; in press.

31. Perez M, Becker, C.B., \& Ramirez, A. Transportability of an empirically supported dissonance-based prevention program for eating disorders. Body image. 2010;7:179-186. 
32. Stice E, Shaw H, Marti CN. A meta-analytic review of obesity prevention programs for children and adolescents: The skinny on interventions that work. Psychological Bulletin. Sep 2006;132(5):667-691.

33. Fairburn CG, Patel V. The global dissemination of psychological treatments: a road map for research and practice. The American journal of psychiatry. May 2014;171(5):495498.

34. Fairburn CG, Wilson GT. The dissemination and implementation of psychological treatments: problems and solutions. The International journal of eating disorders. Jul 2013;46(5):516-521 .

35. Kilpela LS, Hill K, Kelly MC, et al. Reducing eating disorder risk factors: A controlled investigation of a blended task-shifting/train-the-trainer approach to dissemination and implementation. Behav Res Ther. Dec 2014;63:70-82.

36. Proctor E, Silmere H, Raghavan R, et al. Outcomes for implementation research: conceptual distinctions, measurement challenges, and research agenda. Administration and policy in mental health. Mar 2011;38(2):65-76.

37. McFall RM. Consumer satisfaction as a way of evaluating psychotherapy: Ecological validity and all that versus the good old randomized trial (panel discussion). 6th Annual Convention of the American Association of Applied and Preventative Psychology; 1996, July 1; San Francisco.

38. Wade WA, Treat TA, Stuart GL. Transporting an empirically supported treatment for panic disorder to a service clinic setting: a benchmarking strategy. $J$ Consult Clin Psychol. Apr 1998;66(2):231-239. 
39. Stice E, Ziemba, C., Margolis, J., \& Flick, P. The dual pathway model differentiates between bulimics, subclinical bulimics, and controls: Testing the continuity hypothesis. Behavior Therapy. 1996;27:531-549.

40. Stice E, \& Agras, W.S. Predicting onset and cessation of bulimic behaviors during adolescence: A longitudinal grouping analysis. Behavior Therapy. 1998;29(2):257-276.

41. Watson D, Clark LA. Affects Separable and Inseparable - on the Hierarchical Arrangement of the Negative Affects. Journal of Personality and Social Psychology. Mar 1992;62(3):489-505.

42. Berscheid E, Walster, E., \& Bohrstedt, G. The happy American body: A survey report. Psychology Today. 1973;7(119-131).

43. Fairburn CG, Beglin SJ. Assessment of eating disorders: interview or self-report questionnaire? The International journal of eating disorders. Dec 1994;16(4):363-370.

44. Fairburn CGC, Z. . The Eating Disorder Examination (twelfth edition). . New York: Guilford Press; 1993.

45. Luce KH, Crowther JH. The reliability of the Eating Disorder Examination-Self-Report Questionnaire Version (EDE-Q). The International journal of eating disorders. Apr $1999 ; 25(3): 349-351$.

46. Mond JM, Hay PJ, Rodgers B, Owen C, Beumont PJ. Temporal stability of the Eating Disorder Examination Questionnaire. The International journal of eating disorders. Sep 2004;36(2):195-203.

47. Enders CK. Missing not at random models for latent growth curve analyses. Psychological methods. Mar 2011;16(1):1-16. 
48. Little RJA, \& Rubin, D.B. Statistical Analysis with Missing Data. 2 ed. New York John Wiley; 2002.

49. Rubin DB. Inference and missing data (with discussion). Biometrika. 1976;63:581-592.

50. Bollen KA, \& Curran, P.J. . Latent curve models: A structural equation approach. Hoboken, NJ: Wiley; 2006.

51. Muthen L, K., \& Muthen, B.O. Mplus Users Guide. Seventh Edition. Los Angeles, CA: Muthen \& Muthen; 1998-2012.

52. Hu L, \& Bentler, P.M. . Cutoff criteria for $t$ indexes in covariance structure analysis: Conventional criteria versus new alternations. . Structural Equation Modeling. 1999;6:155.

53. Diggle $\mathrm{P}$, \& Kenward, M.G. Informative dropout in longitudinal analysis. Applied Statistics. 1994;43(1):49-93.

54. Little RJA. Modeling the drop-out mechanism in repeated-measure studies. Journal of the American Statistical Association 1995;90:1112-1121. 
Eligible Participants $(\mathrm{n}=124)$

Enrollment: Open Trial $(\mathrm{n}=72)$

Intervention:

Received $1^{\text {st }}$ intervention session only $(\mathrm{n}=72)$

Received complete intervention $(n=48)$

\section{Follow-up:}

Completed follow-up $(\mathrm{n}=28)$

Analysis:

Completed all assessment time points $(\mathrm{n}=28)$

Missing Data Analysis for ITT, $\mathrm{n}=44$ (72-28)

Excluded from analysis, $\mathrm{n}=8$

Reason: Met criteria for likely eating disorder

Total Analyzed, $\mathrm{n}=64$ (72-8)

46 completed T2; 28 completed T3

Figure 1. Consort flowchart showing participant movement through study. 
Table 1

Summary of Logistic Regression Analysis for Variables Predicting Dropout at End of Treatment

Predictor of End of Treatment

$B \quad S E B \quad e^{B}$

Dropout

$\begin{array}{lccc}\text { Baseline TIIS } & -0.061 & 0.617 & 0.941 \\ \text { Baseline PANAS } & 0.686 & 0.568 & 1.461 \\ \text { Baseline SD-BPS } & -0.145 & 0.370 & 0.865 \\ \text { Baseline EDEQ-BN } & -0.496 & 0.451 & 0.609 \\ \text { Baseline BMI } & -0.013 & 0.075 & 0.987 \\ \text { nstant } & -0.539 & & \\ & & 3.466 & \\ & & 5 & \end{array}$

Note: $e^{B}=$ exponentiated $B .{ }^{*} p<.05 .{ }^{* *} p<.01 . * * * p<.001$. 
Table 2

Summary of Logistic Regression Analysis for Variables Predicting Dropout at 5-Month Followup

Predictor of 5-Month Followup

B SEB $e^{B}$

Dropout

$\begin{array}{lccc}\text { Baseline TIIS } & -0.061 & 0.654 & 0.418 \\ \text { Baseline PANAS } & -0.756 & 0.629 & 0.470 \\ \text { Baseline SD-BPS } & 0.228 & 0.450 & 1.257 \\ \text { Baseline EDEQ-BN } & 0.508 & 0.546 & 1.662 \\ \text { Baseline BMI } & -0.032 & 0.073 & 0.968 \\ \text { Change in TIIS Score }^{+} & 0.028 & 0.523 & 1.029 \\ \text { Change in PANAS Score }^{+} & 0.079 & 0.589 & 1.083 \\ \text { Change in SD-BPS Score }^{+} & 0.495 & 0.582 & 1.640 \\ \text { Change in EDEQ-BN Score }^{+} & 1.035 & 0.796 & 2.816 \\ \text { nstant }^{4} & 4.607 & & \\ & & 8.987 & \\ & & & \end{array}$

Note: $e^{B}=$ exponentiated $B .{ }^{*} p<.05 . * * p<.01 . * * * p<.001$.

${ }^{+}=$change in score from baseline to end of treatment. 
Table 3

Estimated Model Means and Standard Deviation for Dependent Variables

\begin{tabular}{|c|c|c|c|c|c|c|}
\hline & Measure & $\begin{array}{l}\text { Baseline } \\
M(S D)\end{array}$ & $\begin{array}{l}\text { Post-Tmt } \\
M(S D)\end{array}$ & $\begin{array}{l}\text { 5-Mo FU } \\
M(S D)\end{array}$ & $\begin{array}{l}\text { Intercept } \\
(S E)\end{array}$ & $\begin{array}{l}\text { Slope } \\
(S E)\end{array}$ \\
\hline \multirow{4}{*}{$\begin{array}{l}\text { Missing } \\
\text { At } \\
\text { Random }\end{array}$} & IBSS-R & $3.61(0.49)$ & $3.12(0.58)$ & $3.27(0.52)$ & $3.608(0.061)^{*}$ & $-0.486(0.089)^{*}$ \\
\hline & SD-BPS & $3.35(1.01)$ & $3.04(0.86)$ & $3.13(1.01)$ & $3.348(0.127)^{*}$ & $-0.313(0.116) * *$ \\
\hline & PANAS & $1.82(0.55)$ & $1.67(0.58)$ & $1.72(0.81)$ & $1.819(0.068)^{*}$ & $-0.147(0.092)$ \\
\hline & EDEQ-BN & $1.36(0.84)$ & $0.96(0.67)$ & $1.00(0.73)$ & $1.348(0.105)^{*}$ & $-0.228(0.060)^{*}$ \\
\hline \multirow{4}{*}{$\begin{array}{l}\text { Diggle } \\
\text { Kenward }\end{array}$} & IBSS-R & $3.61(0.52)$ & $3.05(0.77)$ & $3.11(0.69)$ & $3.706(0.088)^{*}$ & $-0.400(0.104)^{*}$ \\
\hline & SD-BPS & $3.35(1.10)$ & $2.967(1.04)$ & $3.005(1.19)$ & $3.392(0.193) *$ & $-0.328(0.078)^{* * *}$ \\
\hline & PANAS & $1.82(0.65)$ & $1.74(0.68)$ & $1.75(0.87)$ & $1.949(0.098)^{*}$ & $-0.184(0.117)$ \\
\hline & EDEQ-BN & $1.36(0.86)$ & $0.94(0.78)$ & $0.98(0.84)$ & $1.375(0.148)^{*}$ & $-0.427(0.106)^{*}$ \\
\hline \multirow{4}{*}{$\begin{array}{l}\text { Pattern } \\
\text { Mixture } \\
\text { Model }\end{array}$} & IBSS-R & $3.61(0.53)$ & $3.08(0.81)$ & $3.13(0.73)$ & $3.700(0.090)^{*}$ & $-0.397(0.105)^{*}$ \\
\hline & SD-BPS & $3.35(1.06)$ & $2.98(0.97)$ & $3.02(1.04)$ & $3.415(0.185)^{*}$ & $-0.338(0.143) * *$ \\
\hline & PANAS & $1.82(0.62)$ & $1.72(0.63)$ & $1.73(0.84)$ & $1.924(0.099) *$ & $-0.168(0.118)$ \\
\hline & EDEQ-BN & $1.36(0.83)$ & $0.94(0.75)$ & $0.98(0.81)$ & $1.386(0.147)^{*}$ & $-0.431(0.106) *$ \\
\hline
\end{tabular}

Note. ${ }^{*} \mathrm{p}<0.001 ; * * \mathrm{p}<0.01 ; * * * \mathrm{p}<0.05$ 
Table 4

Comparisons of Current Study with Previous Research

\begin{tabular}{|c|c|c|c|c|c|c|c|c|c|}
\hline \multirow[b]{2}{*}{ Measure } & \multicolumn{3}{|c|}{ Post-treatment } & \multicolumn{3}{|c|}{ 5-Month Follow-up } & \multicolumn{3}{|c|}{ Comparison Studies } \\
\hline & $\begin{array}{l}\text { Cohen's } d \\
\text { MAR }\end{array}$ & $\begin{array}{c}\text { Cohen's } d \\
\text { DK }\end{array}$ & $\begin{array}{c}\text { Cohen's } d \\
\text { PMM }\end{array}$ & $\begin{array}{l}\text { Cohen's } d \\
\text { MAR }\end{array}$ & $\begin{array}{c}\text { Cohen's } d \\
\text { DK }\end{array}$ & $\begin{array}{c}\text { Cohen's } d \\
\text { PMM }\end{array}$ & $\begin{array}{l}\text { Cohen's } d \\
\text { 5-Mo FU } \\
\text { Perez et al. } \\
\text { (2010) }\end{array}$ & $\begin{array}{l}\text { Cohen's } d \\
\text { 8-Mo FU } \\
\text { Becker et } \\
\text { al. (2008) }\end{array}$ & $\begin{array}{l}\text { Cohen's } d \\
\text { 8-Mo FU } \\
\text { Becker et } \\
\text { al. (2010) }\end{array}$ \\
\hline IBSS-R & 0.73 & 0.81 & 0.63 & 0.69 & 0.79 & 0.60 & 0.21 & 0.40 & 0.30 \\
\hline SD-BPS & 0.63 & 0.48 & 0.51 & 0.28 & 0.35 & 0.44 & $0.24^{1}$ & $0.37^{1}$ & $0.59^{1}$ \\
\hline PANAS & 0.43 & 0.12 & 0.12 & 0.16 & 0.08 & 0.10 & N/A & N/A & 0.35 \\
\hline EDEQ-BN & 0.74 & 0.72 & 0.51 & 0.62 & 0.58 & 0.45 & 0.41 & 0.37 & 0.55 \\
\hline
\end{tabular}

DK = Diggle-Kenward Model. $\mathrm{PMM}=$ Pattern Mixture Model 